\title{
Increasing the PV hosting capacity of LV networks: OLTC- fitted transformers vs. reinforcements
}

DOI:

10.1109/ISGT.2015.7131856

Link to publication record in Manchester Research Explorer

\section{Citation for published version (APA):}

Navarro, A., \& Ochoa, L. F. (2015). Increasing the PV hosting capacity of LV networks: OLTC-fitted transformers vs. reinforcements. In IEEE/PES Innovative Smart Grid Technologies ISGT 2015 (pp. 1-5) https://doi.org/10.1109/ISGT.2015.7131856

\section{Published in:}

IEEE/PES Innovative Smart Grid Technologies ISGT 2015

\section{Citing this paper}

Please note that where the full-text provided on Manchester Research Explorer is the Author Accepted Manuscript or Proof version this may differ from the final Published version. If citing, it is advised that you check and use the publisher's definitive version.

\section{General rights}

Copyright and moral rights for the publications made accessible in the Research Explorer are retained by the authors and/or other copyright owners and it is a condition of accessing publications that users recognise and abide by the legal requirements associated with these rights.

\section{Takedown policy}

If you believe that this document breaches copyright please refer to the University of Manchester's Takedown Procedures [http://man.ac.uk/04Y6Bo] or contact uml.scholarlycommunications@manchester.ac.uk providing relevant details, so we can investigate your claim.

\section{OPEN ACCESS}




\title{
Increasing the PV Hosting Capacity of LV Networks: OLTC-Fitted Transformers vs. Reinforcements
}

\author{
Alejandro Navarro-Espinosa and Luis F. Ochoa \\ The University of Manchester \\ Manchester, UK \\ alejandro.navarroespinosa@manchester.ac.uk, luis_ochoa@ieee.org
}

\begin{abstract}
The increasing adoption of domestic-scale photovoltaic (PV) systems in the UK is likely to bring significant technical voltage rise issues in low voltage (LV) networks. This work investigates the techno-economic benefits from using onload tap changers (OLTC)-fitted transformers to cope with high penetrations of $P V$. Two voltage regulation approaches are considered: local (busbar) and remote (furthest point). Results are contrasted with traditional network reinforcements. High resolution profiles for residential load and PV systems are used on a real UK LV network. The findings show that the OLTCfitted transformer increases the hosting capacity of the network. The remote approach combined with adequate OLTC design performs better than the local one but the former is only needed for high penetration levels (from $\mathbf{7 0 \%}$ ). Finally, it is shown that the reinforcement alternative is more cost-effective for smaller penetration levels (up to $60 \%$ ) in the network studied and for current prices.
\end{abstract}

Index Terms-- Low voltage networks, OLTC design, photovoltaic systems, voltage regulation

\section{INTRODUCTION}

Nowadays there is a large consensus about the necessity of decreasing the carbon emissions in our society [1]. One alternative to face that challenge is to increase the use of domestic-scale low carbon technologies (e.g., photovoltaic systems, electric heat pumps, electric vehicles, micro combine heat and power, etc.). However, the adoption of these technologies might lead to some problems in low voltage (LV) distribution networks. For example, photovoltaic (PV) systems can produce voltage rise, increase energy losses, produce higher harmonic content, etc. [2].

Typically, voltages at medium voltage (MV) networks (33, 11 , and $6.6 \mathrm{kV}$ in the UK) are managed by using On-Load Tap Changers (OLTC). LV networks $(0.4 \mathrm{kV})$, however, have no voltage regulation means as they simply use off-load tap changing transformers. In this work, the applicability of OLTC technology to LV distribution networks is analyzed. Although a number of studies in the literature consider the potential coordinated control of OLTC-fitted transformers, these are mainly focused on MV networks. In [3], the optimal coordination of reactive power from PV systems and the OLTC is presented to minimize tap operations. This approach was further developed in [4] using a heuristic process and also

This work has partly been funded by Electricity North West Limited (ENWL), UK, through the Ofgem's Low Carbon Networks Fund Tier 1 Project “LV Network Solutions”, 2011-2014. incorporating voltage regulators, shunt capacitors, shunt reactors and static VAR compensators. A similar problem is also solved in [5] but using nonlinear programming tools. All these works, however, rather than adequately modelling the time-series operational aspects of the network elements involved, adopt a day-ahead schedule based on the perfect forecast of loads and generation.

References [6] and [7] investigate the use of OLTC-fitted transformers in LV networks. In both cases, the OLTC is studied adopting a remote control strategy in coordination with the decentralized reactive power control of PV systems without considering any uncertainty. Additionally, [7] shows the economic evaluation of the alternatives presented. Nonetheless, in these two cases, the networks implemented consider PV residential three-phase connections as it is mainly in the German case. Hence, the results presented cannot be extrapolated to networks with single-phase connections (such as in the UK) where the imbalance level can be significant.

This paper assesses the benefits of using OLTC-fitted transformers in $\mathrm{LV}$ networks to increase the penetration of domestic-scale PV systems. A probabilistic approach is used to cope with the uncertainty of LV networks (size and location of the PV system, behavior of the loads, sun irradiance profile). Two voltage regulation approaches are considered: local (fixed voltage target at the busbar) and remote (fixed voltage target at the furthest point). The latter is investigated considering the most adequate OLTC design. To compare the OLTC cost with the network reinforcement cost - business as usual alternative for distribution network operators (DNOs) a reinforcement algorithm is also proposed and implemented.

The rest of the paper is structured as follows: section II describes the LV network model, load/generation profiles used and the case studies. The results for the case studies (without and with OLTC) are presented in section III. Section IV presents the economic assessment of OLTC adoption by comparing it with the network reinforcement cost. Finally, the main conclusions are drawn in section $\mathrm{V}$.

\section{LV NETWORK MODELLING}

The network under analysis, the load/generation profiles developed and the definition of the case studies are presented in this section. 


\section{Accepted Paper}

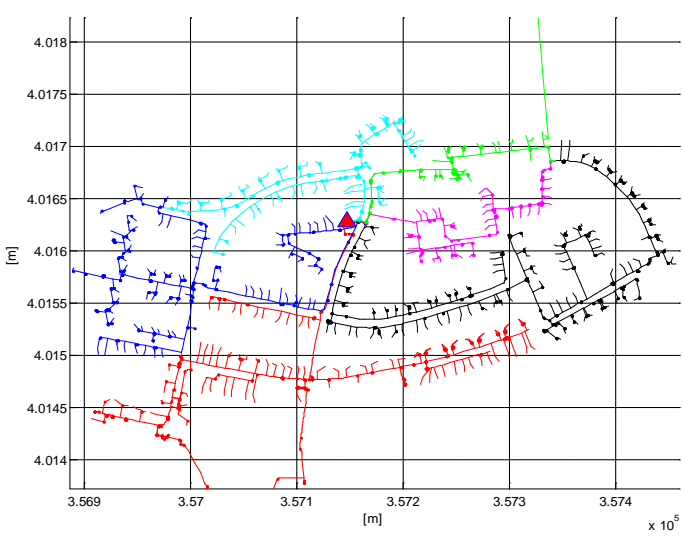

Figure 1. LV network topology.

TABLE 1

LENGTH AND CUSTOMER NUMBER PER FEEDER

\begin{tabular}{c|c|c}
\hline Feeder & Length $(\mathrm{m})$ & No. of Customers \\
\hline 1 & 2479 & 83 \\
\hline 2 & 1823 & 68 \\
\hline 3 & 2312 & 100 \\
\hline 4 & 779 & 30 \\
\hline 5 & 670 & 21 \\
\hline 6 & 1220 & 49 \\
\hline
\end{tabular}

\section{A. LV Network Model and Profiles}

To analyse the benefits of using OLTC-fitted transformers, a real UK LV network is modelled. This network has 6 feeders (three phase), 351 loads (single phase) and $9.2 \mathrm{~km}$ of total length (including the service cables). Fig. 1 shows each feeder in a different colour and the MV/LV substation as a red triangle. The real topology, conductor characteristics, customer locations and phase connection are considered. Table 1 shows the main characteristics in each feeder.

For the analysis carried out in this paper, the creation of residential and PV profiles is needed. The individual load residential profiles are created by using the tool presented in [8]. This tool creates time-series profiles based on the domestic behaviour of British costumers; it takes into account the number of people at home, the type of day, the month, and the uses of the appliances [8]. The PV profiles are elaborated taking into account real sun radiation data for the North West of England (Whitworth Meteorological Observatory at The University of Manchester) and the actual distribution of PV sizes in UK [9].

\section{B. Case Studies}

Two cases are explored using this LV network: base case (transformer with off-load tap changer) and with an OLTCfitted transformer. For the latter, two types of voltage regulation are implemented: local and remote. The local one regulates the voltages at the transformer busbar to achieve a given fixed target. The remote does the same but for furthest point in the network and also considers the most adequate OLTC design. To compare the economic viability of OLTCfitted transformers in LV distribution networks, the cost required by the business as usual network reinforcement is also calculated for the case without OLTC.

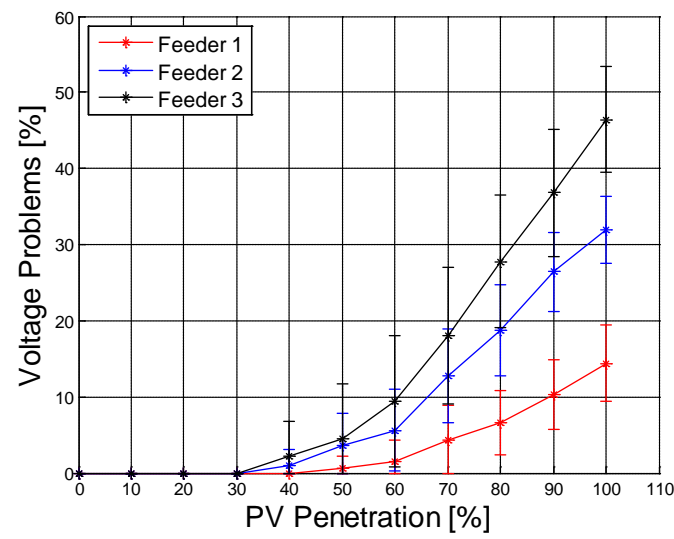

Figure 2. Customers with voltage problems - base case

\section{CASE 1: Base CASE (WITHOUT OLTC)}

In this section, the potential technical impacts of different PV penetrations in a business as usual environment, i.e., offload tap changer-fitted transformers, are presented. The corresponding methodology and metrics to assess these impacts on LV networks are also explained.

\section{A. Methodology}

The procedure to assess the impacts of $\mathrm{PV}$ on $\mathrm{LV}$ distribution networks is based on the Probabilistic Impact Assessment Methodology presented in [10]. The main difference in this case is the simulation of the entire network at the same time in comparison with the feeder by feeder approach implemented in [10]. This adaptation is relevant as it allows assessing the impacts of different busbar voltages on feeders supplied by the same transformer.

The process consists in the random allocation of load and PV profiles through the network in order to deal with the uncertainties related to behaviour and location. This process is carried out for a given penetration level, from 0 to $100 \%$, and repeated one hundred times. For the analysis presented in this work, the penetration level is assumed to be the same in each feeder for a given simulation. For example, $10 \%$ of penetration level means that $10 \%$ of the houses in each feeder have PV systems. It is worth mentioning that in each simulation the same random sun irradiance selected is considered for every house. To assess the impacts, the voltage and thermal rating problems are determined. The percentage of customers with voltage problems according to the BS EN 50160 [12] and the utilization level (thermal loading calculated on hourly basis) of the head of each feeder are determined for each simulation at each penetration level.

\section{B. Results}

Due to the hundred simulations carried out per penetration level, it is possible to present the average value +/- one standard deviation for the voltage and thermal problems. Fig. 2 presents the percentage of customers with voltage problems per penetration level. It can be seen that in average the problems start at $40 \%$ of penetration level. Feeders 4,5 and 6 are not presented in this figure because they do not face any voltage problem for any penetration level. Fig. 3 presents the utilization level at the head of the feeders, showing always an average value lower than the rating capacity (100\%). 


\section{Accepted Paper}

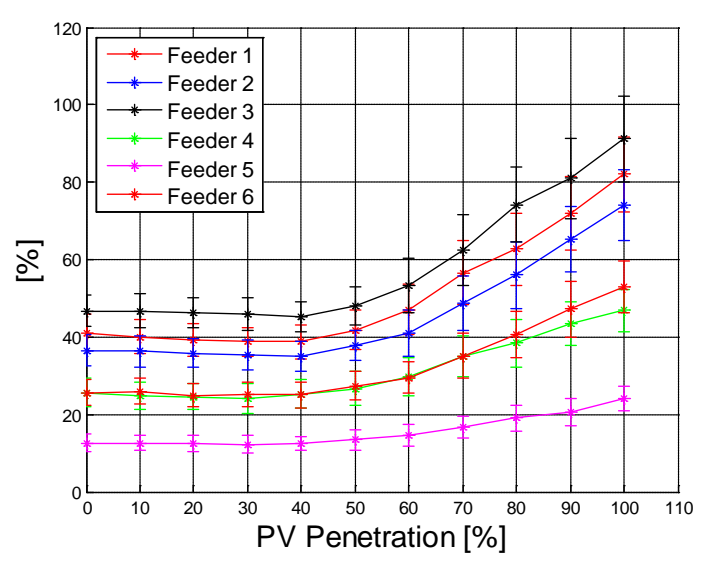

Figure 3. Utilization level at the head of the feeder - base case

Thus, the PV penetration in this particular network is limited by voltage issues (comparison between Fig. 2 and Fig. 3 ), making attractive the use of OLTC-fitted transformer.

\section{CASE 2: OLTC ANALYSIS}

The utilization of transformers with On Load Tap Changer (OLTC) enables varying the ratio between the corresponding primary and the secondary voltages for voltage regulation purposes. Traditionally, the MV/LV transformer cannot change the transformation ratio during operation (the OLTCfitted transformers are often used in higher voltages).

Depending on the location whose voltage is to be regulated, the strategy is classified into local and remote control. Both cases will be analysed in this section. The control cycle adopted for the OLTC is five minutes. To have a fair comparison with the base case, a probabilistic assessment is also developed. One hundred simulations per penetration level are carried out, simulating the daily operation of the OLTC-fitted transformer and calculating the percentage of customers with voltage problems according to the BS EN 50160 standard. The adopted OLTC is considered to be located at the transformer's primary and to have 9 tap positions (with $2 \%$ steps).

\section{A. Local Voltage Regulation}

In this regulation strategy, a fixed voltage target is set at the transformer busbar throughout the day. Given that this target is meant to alleviate voltage rise issues, it has been defined as the minimum voltage that does not produce any voltage drop problem in any of the feeders without PV (i.e., $0 \%$ of penetration level). For the network under study, this value is $235 \mathrm{~V}$ (phase to neutral, 1.02p.u.) for one of the phases at the secondary of the transformer. The adopted regulation capability of the OLTC in this case is $+/-8 \%$.

The percentage of customers with voltage problems is presented in Fig. 4. Issues are delayed from $40 \%$ of PV penetration in the base case (Fig. 2) to $60 \%$ of penetration level (Fig. 4). Also, the magnitude of the problems decreased. For example, at $100 \%$ of penetration level in the base case, the average number of customers with voltage problems in feeder 3 is $46 \%$. In contrast, in the OLTC case with local control, this value is reduced to $18 \%$.

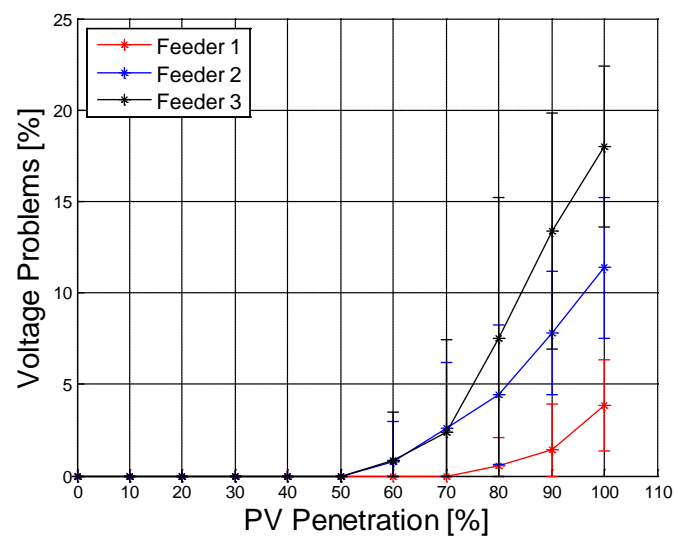

Figure 4. Customers with voltage problems - local control

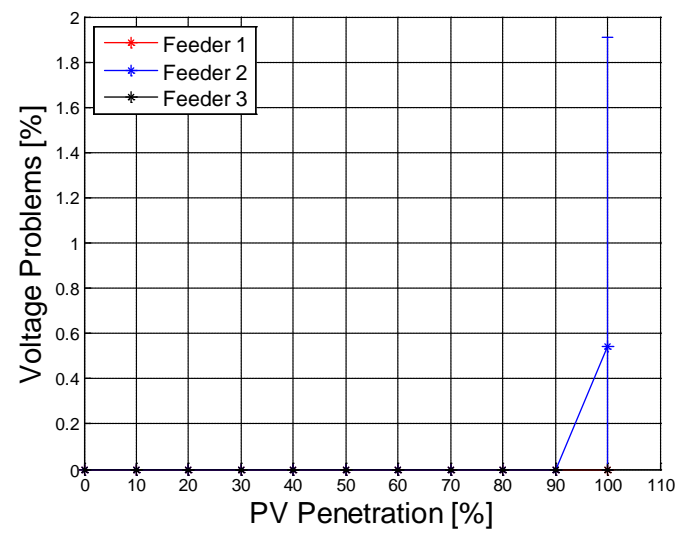

Figure 5. Customers with voltage problems - remote control

\section{B. Remote Voltage Regulation}

In this regulation strategy, a fixed voltage target throughout the day is set at the furthest point in the network. This approach requires a communication system between the OLTC relay and the corresponding remote point whose voltage will be regulated (end point of the longest feeder in the network). This location is based on the fact that the installation of PV panels in the network will mostly affect those customers far from the substation. In addition, the voltage target has to be set such that there is enough headroom for PV generation. For the network under study, this value is $240 \mathrm{~V}$ (phase to neutral, 1.04p.u.) for one of the phases at the furthest point of feeder 1 .

To allow significant reverse power flows (i.e., high PV penetrations) whilst limiting the furthest point in the network to a certain value (in this case $240 \mathrm{~V}$ ), it is important to use an adequate OLTC design. Thus, instead of using a regulation capability of $+/-8 \%$, a range of $+12 /-4 \%$ is adopted in this work (still with 9 tap positions, $2 \%$ steps). This is based on the fact that a higher tap at the transformer's primary implies a lower voltage in the secondary and therefore can minimize the voltage rise produced by high PV penetrations. This design approach extracts the most benefits from the remote strategy.

Again, one hundred simulations per penetration level are carried out. Fig. 5 presents the percentage of customers with voltage problems considering remote voltage regulation. This figure indicates that problems start only at $100 \%$ of PV 


\section{Accepted Paper}

penetration, having in average less than $0.6 \%$ of the customers with problems.

\section{Discussion of Results}

The voltage problems were delayed from $40 \%$ of PV penetration level in the base case to $60 \%$ in the case with OLTC and busbar voltage regulation. This was further shifted to $100 \%$ with remote voltage regulation and an adequate OLTC design. This implies that staged investments can be done in LV networks with progressive penetration of PV systems. Indeed, only the investment in the OLTC with local voltage regulation would be enough to increase the PV penetration level. Further installations of PV systems in the LV network can then trigger the need for the remote voltage regulation strategy and, therefore, the corresponding communications infrastructure. Consequently, the utilization of OLTC-fitted transformers significantly increases the PV hosting capacity of LV networks. To determine when the OLTC alternative is cost-effective, the next section presents an economic comparison between the OLTC cost and the network reinforcement.

\section{ECONOMIC ASSESSMENT}

\section{A. Network Reinforcement}

The traditional approach used by DNOs to face the challenges of load growth is to reinforce the network. This consists in the replacement of conductors for bigger ones to supply the load without violating the thermal ratings. This solution can also be implemented to solve voltage problems given that a bigger cable will have lower impedance and therefore will produce smaller voltage drop (or rise). Hence, this can be considered as one of the business as usual approaches to tackle the potential impacts of PV systems in LV networks. To assess this alternative, a reinforcement methodology is implemented in this work. This calculates the investment cost (investment + installation) required to enable a given PV penetration level. Thus, it is possible to determine the cost for each of the simulations carried out in the probabilistic assessment. The main steps in the reinforcement algorithm for each simulation per feeder are:

1. Determination of all the customers with voltage problems according to BS EN 50160 [11].

2. Identification of the worst location, defined as the customer with the highest voltage rise.

3. Identification of the main path, this is the route between the transformer and the worst location. The main path is divided in segments of 100 metres.

4. The first segment $(100 \mathrm{~m})$ is replaced by the next (larger) conductor size available.

5. A new power flow is run and the voltages are checked.

a. If there are still voltage problems and:

i. If there are more feasible cables, go to step 4 .

ii. If there are not more feasible cables, go to step 4 but for the next segment (next $100 \mathrm{~m}$ ).

b. If there are no more problems or the main path was entirely replaced go to step 6 .

6. The thermal problems are checked for each cable and fixed accordingly.

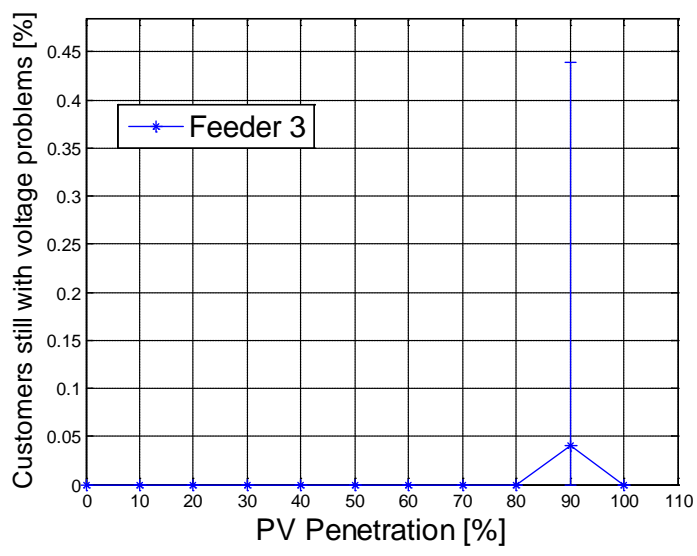

Figure 6. Remaining voltage problems after reinforcements.

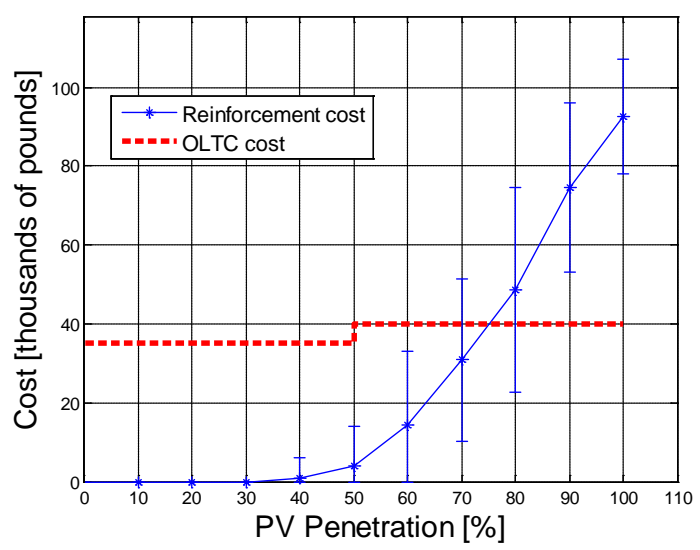

Figure 7. Reinforcement Cost.

This methodology only analyses the replacement of conductors along the main path. Because of this, in some simulations, the voltage problems might not be completely solved. To quantify this phenomenon, the percentage of customers with voltage problems after the reinforcement is also calculated (Fig. 6). In almost every simulation, the network problems were solved. Only feeder 3 , after the reinforcement algorithm, shows 4 customers with voltage issues in one of the simulations at $90 \%$ of penetration level (i.e., the average percentage of customers with voltage problems is lower than 0.05 in Fig. 6).

The installation plus investment cost used in this analysis corresponds to the average value presented in [12] for a UK DNO. This value is equal to $140 £ / \mathrm{m}$ for the main cables and $80 £ / \mathrm{m}$ for the service cables (urban areas). The reinforcement tool is applied for each simulation at each penetration level. Consequently, the total average reinforcement cost (aggregation of reinforcement feeder costs) $+/$ - one standard deviation for each PV penetration level is determined and presented in Fig. 7. There, it is possible to observe that the average network reinforcement cost (cables plus installation cost) at $100 \%$ penetration level is around $£ 93,000$.

\section{B. Analysis of Results}

The current investment cost (equipment plus installation) for a MV/LV OLTC is approximately £36,000 [13]. This represents 3 to 4 times the cost of a traditional $\mathrm{MV} / \mathrm{LV}$ 
transformer. Moreover, the monitoring cost for one location (remote control) is about $£ 4,000$ [13].

The cost of an OLTC-fitted transformer can be compared with the network reinforcement cost calculated previously. It is important to recall that no financial or load/generation growth considerations were taking into account in the simplified reinforcement algorithm developed; only the equipment plus installation cost required for one specific PV penetration level. Thus, the reinforcement cost presented is the cost required to ensure a given penetration level without considering future PV installations or load growth. By comparing this reinforcement cost (Fig. 7) with the base case (Fig. 2) and the two voltage regulation strategies with OLTC (Fig. 4 and Fig. 5), it is possible to observe:

1. For PV penetrations up to $60 \%$, the network reinforcement is the cheapest option. In fact, for $40 \%$ and $50 \%$ of penetration level (the problems are solved with local control), the average reinforcement cost plus one standard deviation is lower than $£ 36,000$. For the $60 \%$ of penetration level (when the remote control is needed), the average cost plus one standard deviation is lower than $£ 40,000$ (OLTC with remote control).

2. The $70 \%$ of penetration level is a transition zone. In fact, there are some cases when the OLTC plus remote monitoring is cheaper than the reinforcement cost.

3. For PV penetrations above $70 \%$, the reinforcement cost is more expensive than using an OLTC-fitted transformer with remote control. In this range, the OLTC solved all the problems for $80 \%$ and $90 \%$ of penetration level and for $100 \%$ of penetration level the problems were minimized to less than $1 \%$ in average.

These results indicate that if a DNO expects a lower penetration level in one particular network (e.g., physical constraints such as house orientation, available roof surface or socioeconomic limitations), the reinforcement of the network is cheaper than the OLTC-fitted transformer option. In contrast, if a DNO expects a higher PV penetration level or if they want to be prepared for $100 \%$ of PV penetration, then the OLTC is cheaper than the network reinforcement cost. Furthermore, if the DNO wants to be prepared for a $100 \%$ of PV penetration and this level is expected to be reached gradually, then the investment in remote monitoring and the incorporation of more sophisticated control algorithms for the OLTC can be done progressively with the further installations of PV systems.

\section{CONCLUSIONS}

A techno-economic assessment of the potential benefits from using OLTC-fitted transformers to increase the PV hosting capacity of LV networks was presented in this paper. A probabilistic approach was used to cope with the uncertainty of LV networks (size and location of the PV, behaviour of the loads and sun irradiance). One hundred simulations were executed per penetration level (as percentage of houses and evenly distributed among feeders). In each simulation, the OLTC voltage regulation strategy considered a control cycle of 5 minutes and two cases: busbar and remote voltage regulation. The latter was investigated considering the most adequate OLTC design. Finally, the cost of the OLTCfitted transformer was compared with the network reinforcement cost (business as usual alternative for DNOs).

The results on a real UK LV network indicate that OLTCfitted transformers can significantly improve the PV hosting capacity. The occurrence of voltage problems according to the BS EN 50160 standard were shifted from $40 \%$ of PV penetration without OLTC to $60 \%$ in the case with busbar voltage regulation. This figure increases to $100 \%$ in the case with remote regulation. Results also highlight the possibility to make staged investments (i.e., remote voltage regulation is adopted at a later stage) in networks with progressive PV penetrations. The investment analysis also suggests that for smaller PV penetrations (up to 60\%) traditional reinforcement is more cost-effective than the OLTC-fitted transformer under the current OLTC prices in the UK.

\section{REFERENCES}

[1] IPCC, "Summary for Policymakers. In: Climate Change 2013: The Physical Science Basis. Contribution of Working Group I to the Fifth Assessment Report of the Intergovernmental Panel on Climate Change,” 2013.

[2] R. A. Walling, R. Saint, R. C. Dugan, J. Burke, and L. A. Kojovic, "Summary of Distributed Resources Impact on Power Delivery Systems,” IEEE Trans. Power Deliv., vol. 23, no. 3, pp. 1636-1644, 2008.

[3] Y. P. Agalgaonkar, B. C. Pal, and R. A. Jabr, "Distribution Voltage Control Considering the Impact of PV Generation on Tap Changers and Autonomous Regulators," IEEE Trans. Power Syst., pp. 1-11, 2013.

[4] M. Oshiro, K. Tanaka, A. Uehara, T. Senjyu, Y. Miyazato, A. Yona, and T. Funabashi, "Optimal voltage control in distribution systems with coordination of distribution installations," Int. J. Electr. Power Energy Syst., vol. 32, no. 10, pp. 1125-1134, Dec. 2010.

[5] S. Paudyal, C. A. Cañizares, and K. Bhattacharya, "Optimal Operation of Distribution Feeders in Smart Grids," IEEE Trans. Ind. Electron., vol. 58, no. 10, pp. 4495-4503, 2011.

[6] P. Esslinger and R. Witzmann, "Regulated distribution transformers in low-voltage networks with a high degree of distributed generation," in 3rd IEEE PES Innovative Smart Grid Technologies Europe (ISGT Europe), 2012, pp. 1-7.

[7] T. Stetz, F. Marten, and M. Braun, "Improved Low Voltage GridIntegration of Photovoltaic Systems in Germany," IEEE Trans. Sustain. Energy, vol. 4, no. 2, pp. 534-542, Apr. 2013.

[8] I. Richardson, M. Thomson, D. Infield, and C. Clifford, "Domestic electricity use: A high-resolution energy demand model," Energy Build., vol. 42, no. 10, pp. 1878-1887, Oct. 2010.

[9] Department of Energy and Climate Change, "Weekly Solar PV Installation and Capacity based on Registration Date,” 2012.

[10] A. Navarro, L. F. Ochoa, and D. Randles, "Monte Carlo-Based Assessment of PV Impacts on Real UK Low Voltage Networks," in 2013 IEEE Power and Energy Society General Meeting, 2013, pp. 15.

[11] Brisitsh Standards Institution, "BS EN 50160: Voltage characteristics of electricity supplied by public distribution systems," 2000.

[12] "Statement Charges of Methodology and Charges for Connection to ENWL's Electricity Distribution System - Effective From: 06 November 2013,” 2013. [Online]. Available: http://www.enwl.co.uk/docs/default-source/connections/statement-ofmethodology-and-connection-charges-(06-nov-2013).pdf?sfvrsn=4.

[13] Electricity North West Limited, "ETA: Creating efficient distribution networks,” 2013. 